\title{
ACUTE RHINOSINUSITIS : NASONEX AS ADJUNCTIVE THERAPY
}

\author{
By \\ Mahmoud A Yosef and Sameh M. Hakim
}

\begin{abstract}
From
"Assistant Professor of Otorhinolaryngology, Faculty of Medicine, Mansoura University. " "Lecturer of Anesthesiology, Faculty of Medicine, Ain Shams University.
\end{abstract}

\section{ABSTRACT}

This study evaluates the effectiveness and safety of mometasone furoate nasal spray (MFNS; Nasonex®, Schering, Kenilworth, NJ) as adjunctive treatment with oral antibiotic; amoxicillin/clavulanate potassium (ACP; Augmentin $®$, GlaxoSmithKline, Research Triangle Park, NC) for acute rhinosinusitis. In a double-blind, placebo-controlled study, 75 outpatients with moderate to severe rhinosinusitis received ACP, $875 \mathrm{mg}$, twice daily, for 21 days with adjunctive twice daily MFNS $200 \mu \mathrm{g}$, MFNS $400 \mu \mathrm{g}$, or placebo nasal spray. MFNS significantly improves the symptoms of rhinosinusitis. Both doses of MFNS were well tolerated without significant treatment-related adverse events.

\section{INTRODUCTION}

Rhinosinusitis is a common disease, which has a significant clinical and economic impact on both the society and the affected individuals. There are many local and systemic predisposing factors for rhinosinusitis. The most common of these are viral upper respiratory tract infections and allergic rhinitis. Inflammation can lead to swelling of the mucosa, which causes obstruction of the sinus ostia, decreased ciliary action, and increased mucus production and viscosity. The subsequent retention of secretions provides an environment for secondary bacterial infection with the conversion of mucus to mucopus, which further impairs the ciliary action, increasing the swelling around the ostia, creating a vicious cycle. The 
obstruction, mucus retention, and infection produce the signs and symptoms characteristic of rhinosinusitis, including purulent rhinorrhea, postnasal drip, and cough that persist beyond the 7 to 10 days typical of an upper respiratory tract viral infection. Additional symptoms may include nasal obstruction, headache, and/or facial pain. The diagnosis of rhinosinusitis can be confirmed by sinus imaging with coronal computed tomography (CT).

Acute rhinosinusitis is currently defined as an inflammation of the sinuses with the symptoms complex lasting less than 4 weeks (1-2). With appropriate therapy, the symptoms and signs of acute rhinosinusitis usually resolve completely. The goals of treatment are to eradicate the pathogens, allow sinus drainage, and stop the tissue damage. Antibiotics are generally the first line of treatment to control the bacterial infections; however, anti-inflammatory treatment may also be necessary. Topical washings, expectorants, and nasal decongestants may improve sinus drainage (3).

Glucocorticoids as anti-inflammatory can be used to reduce muco- sal swelling and facilitate drainage, reduce eosinophilia in inflamed tissues, making them potentially useful in rhinosinusitis management. Also, the efficacy of intranasal glucocorticoids has been demonstrated for seasonal allergic rhinitis and moderate-to-severe exacerbation of perennial rhinitis, possible predisposing factors to the development of acute rhinosinusitis. MFNS is potent, topically active, synthetic glucocorticoids, which has been formulated for dermatological use and also formulated as a nasal spray approved for the treatment of seasonal and perennial allergic rhinitis in adults and children(4-6).

Although guidelines reflect the belief of many clinicians that intranasal glucocorticoids are a valuable component for acute rhinosinusitis management, limited clinical data are available on their use in this disease. The objective of the present placebocontrolled clinical trial is to evaluate the effectiveness, dose, duration and safety of MFNS as adjunctive therapy with oral antibioti $c$ therapy in the treatment of acute rhinosinusitis.

\section{PATIENTS AND METHODS}

This study was a 21-day, random- 
ized, double-blinded, placebocontrolled trial conducted, from October 2002 to March 2003. Patients aged $\geq 18$ years with symptoms characteristic of an acute rhinosinusitis, were evaluated for inclusion in the study. Medical history and physical examination including vital signs, E.N.T. examination, and complete blood picture were undertaken to ensure that patients were clinically free of other significant diseases. Patients with recent sino- nasal surgery, cystic fibrosis, nasal polyps, Kartagener syndrome, glaucoma, or a history of subcapsular cataracts were excluded. Patients on intranasal or systemic glucocorticoids, decongestants and systemic antibiotics were excluded as well.

Six symptoms, viz., congestion, facial pain, sinus headache, purulent rhinorrhea, postnasal drip, and cough; were evaluated by both the investigator and the patient according to the following scale:

$0=$ none (symptoms were not present);

1 = mild (symptoms were present, but causing little or no discomfort); 2 = moderate (symptoms were present, annoying and causing discomfort); and 3 = severe (symptoms were very marked and interfering with daily activities).

For patients to be eligible for randomization, the total symptoms score (TSS) was to be ${ }^{\circ}, 6$. At least one nasal symptom was to be moderate or severe, and purulent rhinorrhea was to be present. Limited coronal paranasal CT scans at the baseline visit i.e. at day-1, had to show evidence of rhinosinusitis (judged as clinically significant mucosal thickening, opacification, or air/fluid levels) in one or more sinuses to satisfy inclusion criteria.

Eligible patients who satisfied the inclusion and exclusion criteria received 21 days of treatment with the oral antibiotic (ACP); $875 \mathrm{mg}$, twice daily, and were randomized to receive twice daily MFNS $200 \mu \mathrm{g}$, MFNS 400 $\mu \mathrm{g}$ or placebo in a 1:1:1 ratio.

\section{STATISTICAL ANALYSIS}

Data were analyzed using the Statistical Package for Social Sciences version 10.0 (SPSS $\odot 10.0$, SPSS Inc.) on a personal computer. Normally distributed numerical data were presented as mean (standard deviation) and differences between means were compared using one-way analy- 
sis of variance (ANOVA). Nominal data were presented as ratio or as number [\%] and differences between groups were compared using the $\mathrm{X} 2$ test with application of Fisher's exact test when appropriate. Categorical data were presented as median (interquartile range) and inter-group differences were compared nonparametrically using the KruskalWallis test. The Mann-Whitney Utest was applied post hoc whenever a significant difference among the groups was found. Paired categorical data were compared nonparametrically using Wilcoxon's signed ranks test. $P<0.05$ was considered significant.

\section{RESULTS}

A total of 75 patients met the initial evaluation criteria and were randomized to one of the three treatment groups: ACP with MFNS 200 $\mu$ g, twice daily (MFNS $200 \mu \mathrm{g}$ group, $\mathrm{n}=25$ ); ACP with MFNS $400 \mu \mathrm{g}$, twice daily (MFNS $400 \mu \mathrm{g}$ group, $n=25$ ); and $A C P$ with placebo (placebo group, $n=25)$.

There was no significant difference between the three groups as regards age, sex, weight, and height on day-1 (table, 1).

Vol. 34, No. 3 \& 4 July., \& Oct, 2003
There was no significant difference between the three groups as regards TSS, congestion score, headache score, postnasal drip score or cough score on day- 1 .

However, there was significant difference between MFNS $200 \mu \mathrm{g}$ group and placebo group as regards facial pain score and purulent rhinorrhea score $(P<0.01)$. Also, there was significant difference between MFNS $400 \mu \mathrm{g}$ group and placebo group as regards facial pain score $(P<0.001)$, and between MFNS $400 \mu \mathrm{g}$ group and MFNS $200 \mu \mathrm{g}$ group as regards purulent rhinorhea score $(P<0.01)$ (table, 2).

The TSS, congestion score, headache score, purulent rhinorrhea score, postnasal drip score and cough score, on day 15 , were all significantly less in MFNS $200 \mu \mathrm{g}$ group and MFNS $400 \mu \mathrm{g}$ group as compared to placebo group (table, 3).

The TSS, congestion score, purulent rhinorrhea score, postnasal drip score and cough score, on day 21 , were all significantly less in MFNS $200 \mu \mathrm{g}$ group and MFNS $400 \mu \mathrm{g}$ group as compared to placebo group (table, 4). 
There was no significant differ-

There was no significant ence among any of the symptoms difference among the three score and TSS obtained on day 15 groups as regards treatmentand that obtained on day 21, in any related adverse events (table, of the three groups (table, 5).

$6)$.

Table1. Demographic characteristics.

\begin{tabular}{|l|l|l|l|}
\hline & Placebo GP & MNFS 200 $\mu \mathrm{g}$ GP & MFNS 400 $\mu \mathrm{g} \mathrm{GP}$ \\
\hline Age (yr) & $29(7)$ & $30(8)$ & $28(7)$ \\
\hline Male/female & $11 / 14$ & $14 / 11$ & $10 / 15$ \\
\hline Weight (kg) & $66(6)$ & $71(13)$ & $69(10)$ \\
\hline Height (cm) & $165(6)$ & $167(7)$ & $166(6)$ \\
\hline
\end{tabular}

Data are mean (standard deviation) or ratio.

There is no significant difference among the three groups.

Table (2): Symptoms scores at day-1.

\begin{tabular}{|l|l|l|l|}
\hline & Placebo GP & MNFS 200 $\mu \mathrm{g}$ GP & MFNS 400 $\mu \mathrm{g}$ GP \\
\hline Congestion & $3(2-3)$ & $2(1-2)$ & $2(2-2)$ \\
\hline Facial Pain & $1(1-2)$ & $2(1-2)^{\dagger}$ & $2(2-2)^{\ddagger}$ \\
\hline Headache & $2(1-2)$ & $2(1-2)$ & $2(2-2)$ \\
\hline Purulent Rhinorrhea & $2(2-2)$ & $2(1-2)^{\dagger}$ & $2(2-2)^{\zeta}$ \\
\hline Postnasal drip & $2(2-2)$ & $2(2-2)$ & $2(2-2)$ \\
\hline Cough & $2(2-2)$ & $2(1-2)$ & $2(1-2)$ \\
\hline TSS & $12(10-12)$ & $11(10-12)$ & $12(11-13)$ \\
\hline
\end{tabular}

Data are median (interquartile range).

${ }^{t} \mathrm{P}<0.01$ compared with placebo.

$: \mathrm{P}<0.001$ compared with placebo.

${ }^{5} \mathrm{P}<0.01$ compared with $200 \mu \mathrm{g}$.

Table (3): Symptoms scores at day-15.

\begin{tabular}{|c|c|c|c|}
\hline & Placebo GP & MFNS $200 \mu \mathrm{g}$ GP & MFNS $400 \mu \mathrm{g}$ GP \\
\hline Congestion & $2(1-2)$ & $1(1-1)^{\frac{7}{2}}$ & $1(1-1)^{50}$ \\
\hline Facial Pain & $1(0-1)$ & $1(0-1)$ & $1(0-1)$ \\
\hline Headache & $1(1-1)$ & $1(0-1)^{*}$ & $1(0-1)$ \\
\hline Purulent Rhinorrhea & $1(1-2)$ & $1(0-1)^{+}$ & $1(1-1)^{+}$ \\
\hline Postnasal drip & $2(1-2)$ & $1(1-1)^{\ddagger}$ & $1(1-1)^{\dagger}$ \\
\hline Cough & $1(1-2)$ & $1(1-1)^{*}$ & $1(0-1)^{?}$ \\
\hline TSS & $7(5-9)$ & $5(4-6)^{2}$ & $6(3-6)^{!}$ \\
\hline
\end{tabular}

Data are median (interquartile range).

P $<0.05$ compared with placebo.

+ $\mathrm{P}<0.01$ compared with placebo.

: $\mathrm{P}<0.001$ compared with placebo.

${ }^{\circ} \mathrm{P}<0.05$ compared with $400 \mu \mathrm{g}$. 
Table (4): Symptoms scores at day-21.

\begin{tabular}{|l|l|l|l|}
\hline & Placebo GP & MFNS 200 $\mu \mathrm{g}$ GP & MFNS 400 $\mu \mathrm{g}$ GP \\
\hline Congestion & $2(1-2)$ & $1(0-2)^{\dagger}$ & $1(0-1)^{\dagger}$ \\
\hline Facial Pain & $1(0-1)$ & $1(0-1)$ & $1(0-1)$ \\
\hline Headache & $1(0-1.5)$ & $1(0-1)$ & $1(0-1)$ \\
\hline Purulent Rhinorrhea & $1(1-1)$ & $1(0-1)^{\dagger}$ & $1(0-1)^{\dagger}$ \\
\hline Postnasal drip & $1(1-2)$ & $1(0-1)^{\star}$ & $1(0-1)^{\star}$ \\
\hline Cough & $1(1-2)$ & $1(0.5-1)^{\dagger}$ & $1(0-1)^{\dagger}$ \\
\hline TSS & $7(5-10)$ & $4(2.5-6)^{\dagger}$ & $6(1.5-7)^{\dagger}$ \\
\hline
\end{tabular}

Data are median (interquartile range).

$\mathrm{P}<0.05$ compared with placebo.

$+\mathrm{P}<0.01$ compared with placebo.

Table (5): Symptoms scores at day-15 vs. TSS at day-21

\begin{tabular}{|l|l|l|l|l|l|l|}
\hline & \multicolumn{3}{|c|}{ Placebo GP } & \multicolumn{2}{c|}{ MFNS 200 $\mu$ g GP } & \multicolumn{1}{c|}{ MFNS 400 $\mu$ g GP } \\
\hline & $15-$ day & $21-$ day & 15 -day & 21 -day & $15-$ day & 21 -day \\
\hline Congestion & $2(1-2)$ & $2(1-2)$ & $1(1-1)$ & $1(0-2)$ & $1(1-1)$ & $1(0-1)$ \\
\hline Facial Pain & $1(0-1)$ & $1(0-1)$ & $1(0-1)$ & $1(0-1)$ & $1(0-1)$ & $1(0-1)$ \\
\hline Headache & $1(1-1)$ & $1(0-1.5)$ & $1(0-1)$ & $1(0-1)$ & $1(0-1)$ & $1(0-1)$ \\
\hline Purulent Rhinorrhea & $1(1-2)$ & $1(1-1)$ & $1(0-1)$ & $1(0-1)$ & $1(1-1)$ & $1(0-1)$ \\
\hline Postnasal drip & $2(1-2)$ & $1(1-2)$ & $1(1-1)$ & $1(0-1)$ & $1(1-1)$ & $1(0-1)$ \\
\hline Cough & $1(1-2)$ & $1(1-2)$ & $1(1-1)$ & $1(0.5-1)$ & $1(0-1)$ & $1(0-1)$ \\
\hline TSS & $7(5-9)$ & $7(5-10)$ & $5(4-6)$ & $4(2.5-6)$ & $6(3-6)$ & $6(1.5-7)$ \\
\hline
\end{tabular}

Data are median (interquartile range).

There is no significant difference between the three groups.

Table (6): Treatment-related adverse Events.

\begin{tabular}{|c|c|c|c|}
\hline & Placebo GP & MFNS $200 \mu \mathrm{g}$ & MFNS $400 \mu \mathrm{g}$ \\
\hline Epistaxis & $1[4 \%]$ & 0 & $1\{4 \%\}$ \\
\hline Nasal burning/irritation & 0 & $1[4 \%]$ & 0 \\
\hline
\end{tabular}

Vol. 34, No. 3 \& 4 July., \& Oct, 2003 


\section{DISCUSSION}

Two essential components of acute rhinosinusitis management are the eradication of bacterial pathogens and the inhibition of the inflammatory process. Treatment of acute rhinosinusitis with standard antibiotic therapy eliminates the bacterial infection; while the use of intranasal glucocorticoids, such as MFNS, locally inhibits the inflammatory process (7).

The antibiotic treatment (ACP) was chosen based on the fact that it is the most widely used treatment for rhinosinusitis and it is efficacious against the most probable pathogens, including Haemophilus influenzae, Streptococcus pneumoniae, and Moraxella catarralis ${ }^{(8)}$. A 14-days course is probably adequate for most patients with acute rhinosinusitis, but to increase the likelihood of bacterial eradication, ACP $875 \mathrm{mg}$, twice daily, was given for 21-days rather than the generally prescribed 10 to 14 days (1, 9).

Recer: practice guidelines for the management of rhinosinusitis suggest considering the use of intranasal glucocorticoids as adjunctive treatment that combat the pathophysiological process of sinusitis at many levels, in- cluding reduction of mucosal inflammation responsible for ostial obstruction, prevention of bacterial growth, and potentiation of normal mucosal regeneration (10-12).

Recent animal studies have shown that low doses of glucocorticoids exhibit immunopotentiating and protective effects during the early phases of bacterial airway infection, while high doses administered for prolonged periods may have immunosuppressive effects. The immunopotentiating effects of glucocorticoids on the host defense systems lead to inhibition of bacterial colonization, and growth. Also, it enhances the mucosal regeneration, while inhibiting polyp formation $(13,14)$.

MFNS is the most effective pharmacological agent for treating and preventing inflammation associated with allergic rhinitis, which is one of the most common predisposing factors of acute rhinosinusitis $(4,6,10,15,16)$. Its anti-inflammatory properties have been demonstrated in vitro and vivo(4). It has been suggested that MFNS might be beneficial in the treatment of acute rhinosinusitis by reducing the inflammatory response and, therefore, mucosal swell- 
ing. These actions increase aeration of the sinuses, promote drainage, contribute to the elimination of infectious organisms, and decrease the frequency and severity of acute episodes of rhinosinusitis $(7,8,10,13)$.

Studies of MFNS in adults and children with allergic rhinitis showed both a lake of hypothalamic-pituitaryadrenal axis suppression and of childhood growth suppression and are consistent with extremely low bioavailability of mometasone furate after intranasal administration (17-19).

In a recent report of more than 400 patients with recurrent rhinosinusitis, adjunctive treatment with MFNS 400 $\mu \mathrm{g}$, twice daily, was effective in relieving rhinosinusitis symptoms, particularly those related to inflammatory swelling (i.e., congestion, facial pain, and headache) compared with the antibiotic and placebo. Recurrent rhinosinusitis may involve an underlying chronic inflammation, which becomes worsening during acute episodes. Compared with ACP/ placebo, the additional relief of symptoms of recurrent rhinosinusitis provided by the use of adjunctive MFNS seemed to develop over 6 to 7 days. Thus, the relief of recurrent rhinosinusitis by adjunctive MFNS may develop more slowly than relief of acute rhinosinusitis (11).

In the present study, the relief of symptoms of acute rhinosinusitis with the addition of MFNS either $200 \mu \mathrm{g}$, or $400 \mu \mathrm{g}$ to ACP was highly significant compared with ACP and placebo, at day 15 and day $21(P<0.001)$. As regards MFNS dosage, the efficacy of MFNS $400 \mu \mathrm{g}$ in relieving nasal congestion was significant compared with MFNS $200 \mu \mathrm{g}$, at day 15. Also, as regards the duration of treatment, there was no significant difference in the efficacy to relieve symptoms between the two MFNS doses, either at day 15 or day 21.

Treatment with MFNS up to 400 $\mu \mathrm{g}$ for 21 days was well tolerated, and all treatment-related adverse events that reported were of mild or moderate intensity. The incidence of treatment-related adverse events was similar for all the three treatment groups [4\%]. In one patient, treatment discontinued because of adverse events, most commonly diarrhea and nausea because of ACP, and was excluded from the study. Epistaxis, nasal irritation or nasal burning was not a cause of discontinuation of treatment. 


\section{CONCLUSION}

The results of this 21-day placebocontrolled study support the current clinical rationale of adding an intranasal glucocorticoid to the antibiotic therapy for the treatment of acute rhinosinusitis. The relief of symptoms by the addition of mometasone furate nasal spray to amoxicillin/clavulanate potassium was highly significant than that obtained by amoxicillin/ clavulanate potassium and placebo. But, there was no significant difference to use MFNS either $200 \mu \mathrm{g}$ or $400 \mu \mathrm{g}$.

Also, there was no significant difference to use MFNS either for 15 or 21 days. MFNS was effective and well tolerated at dosages up to 400 $\mu \mathrm{g}$, twice daily.

\section{REFRENCES}

1. Spector SL, Bernstien IL, Li JT et al. (1998) : Parameters for the diagnosis and management of sinusitis. J Allergy Clin Immunol; 102(suppl): 107-144.

2. Kaliner MA, Osguthorpe JD, Fireman P, et al. (1997) : Sinusitis: bench to bedside. Current findings, future directions. $\mathrm{J}$ Allergy Clin Immunol; 99(suppl): 829-848.

3. Benninger MS, Anon J, Mabry RL. (1997) : The medical management of rhinosinusitis. Otolaryngol Head Neck Surg; 117(suppl): 41-49.

4. Meltzer EO, Jalowayski AA, Orgel HA, Harris AG. (1998) : Subjective and objective assessments in patients with seasonal allergic rhinitis: effects of therapy with mometasone furate nasal spray. J Allergy Clin Immunol; 102:3949.

5. Mygind N. (1999) : Advances in the medical treatment of nasal polyps. Allergy; 54(suppl): 12 16.

6. Berkowitz RB, Roberson S, Zora J, et al. (1999) : Mometasone furate nasal spray is effective in the treatment of seasonal allergic rhinitis in an outdoor (park) acute exposure setting. Allergy Asthma Proc.; 20:167172.

7. Qvarnberg Y, Kantola O, Salo J, et al. (1992) : Influence of 
topical steroid treatment on maxillary sinusitis. Rhinology; 30:103-112.

8. Chow AW, Hall CB, Klein JO, et al. (1992) : Evaluation of new anti-infective drugs for the treatment of respiratory tract infections. Infectious Diseases Society of America and the Food and Drug Administration. Clin Infect Dis; 15 (suppl): S62-S88.

\section{Meltzer EO, Orgel HA, Backhaus} JW, et al. (1993) : Intranasal flunisolide spray as an adjunct to oral antibiotic therapy for sinusitis. J Allergy Clin Immunol; 92: 812-823.

10. Cuenant G, Stipon JP, PlanteLongchamp C, Guerrier Y. (1986) : Efficacy and endonasal neomycin-tixocortol pivalate irrigation in the treatment of chronic allergic and bacterial sinusitis. ORL J Otorhinolaryngol Relat Spec.; 48:226232.

11. Meltzer EO, Charous BL, Busse WW, et al. (2000) : Added relief in the treatment of acute recurrent sinusitis with adjunctive mometasone furate nasal spray. The Nasonex sinusitis group. J Allergy Clin Immunol; 106: 630- 637.

12. Barlan IB, Kerkan E, Bakir M, Berrak S, Basaran MM. (1997) : Intranasal budesonide spray as an adjunct to oral antibiotic therapy for acute sinusitis in children. Ann Allergy Asthma Immunol; 78:598-601.

13. Norlander T, Kwon S-H, Henriksson $\mathrm{O}$, Westrin $\mathrm{KM}$, Stierna P. (1998) : The effect of systemic pre-treatment with betamethasone on the bacterial flora, inflammatory response, and polyp formation in experimentally infected rabbit maxillary sinus mucosa. Laryngoscope.; 108:411. 417.

14. Forsgren $\mathrm{K}$, Westrin $\mathrm{KM}$, Fukami M, Stierna P. (1997) : Effects of surgery on mucosal pathology following experimental sinusitis in rabbits. Annals Otol Rhinol Laryngol.; 107:155-163. 
15. Tsang RKY, Tong MCF, Woo JKS, and Hasselt CAV. (2003) : A prospective study on the efficacy of mometasone furate monohydrate aqueous nasal spray on Chinese patients with allergic rhinitis. Otolaryngology-Head and Neck surgery.; 128:497502.

16. Gawchik S, Goldstein S, Prenner B, and John A. (2003) : Relief of cough and nasal symptoms associated with allergic rhinitis by mometasone furate nasal spray. Ann Allergy Asthma Immunol; 90:416-421.

17. Davies RJ, Nelson HS. (1997) :
Once-daily mometasone furate nasal spray: efficacy and safety of a new intranasal glucocorticoid for allergic rhinitis. Clin Ther; 19: 27-38.

18. Brannan MD, Herron JM, Affrime MB. (1997) : Safety and tolerability of once-daily mometasone furate aqueous nasal spray in children. Clin Ther; 19:1330-1339.

19. Schenkel EJ, Skoner DP, Bronsky EA, et al. (2000) : Absence of growth retardation in children with perennial allergic rhinitis after one year of treatment with mometasone furate aqueous nasal spray. Pediatrics; 105: E22. 


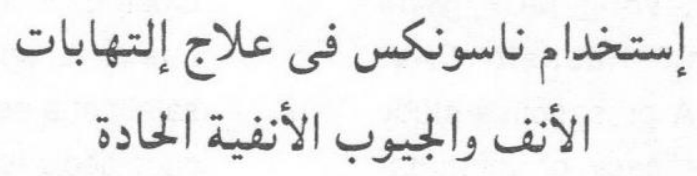

قمنا بدراسة فعالبة إستخدام بخاخة الأنف ناسونكس كعلاج مساعد مع المضاد الحيوى فى علاج

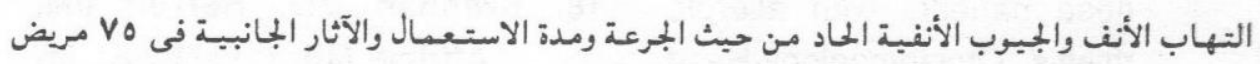

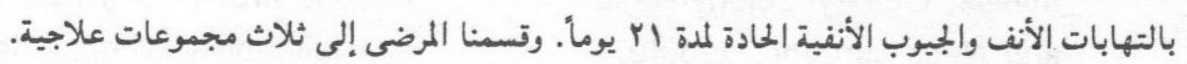

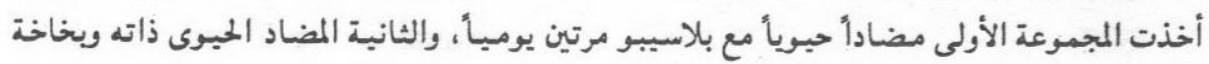

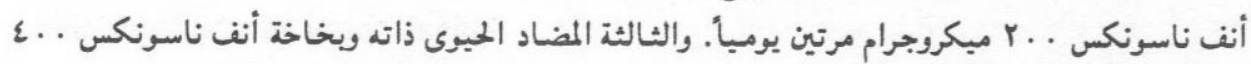

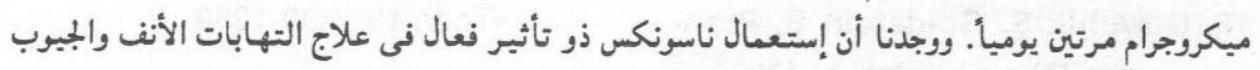
الأنفية الحادة وليس له آثار جانبية تذكر. 